\title{
Urgences
}

\section{On raconte...}

\section{Mario Canuel}

Numéro 5, 3e trimestre 1982

URI : https://id.erudit.org/iderudit/025072ar

DOI : https://doi.org/10.7202/025072ar

Aller au sommaire du numéro

Éditeur(s)

Urgences

ISSN

0226-9554 (imprimé)

1927-3924 (numérique)

Découvrir la revue

Citer ce document

Canuel, M. (1982). On raconte... Urgences, (5), 15-22.

https://doi.org/10.7202/025072ar

Ce document est protégé par la loi sur le droit d'auteur. L'utilisation des services d'Érudit (y compris la reproduction) est assujettie à sa politique d'utilisation que vous pouvez consulter en ligne.

https://apropos.erudit.org/fr/usagers/politique-dutilisation/ 


\section{MARIO CANUEL}


on raconte qu'un enfant faisait en claquant ses doigts un son nouveau que lui seul possédait les vieux frustrés firent tout pour l'imiter mais ils n'y parvinrent jamais car ce bruit était celui d'un monde nouveau. 


\section{LA LEÇON}

je suis resté après l'école pour faire les tableaux j'ai eu congé de leçon j'ai descendu les escaliers sans tenir la rampe on s'est mis en rangs les oreilles à Lavoie en avant le grand Desrosiers le fils du policier en arrière

j'ai appris par coeur pour demain

j'ai porté la cravate

j'ai demandé la permission d'aiguiser mes crayons j'ai regardé dehors j'étais dans la lune je suis allé en récréation je ne suis pas sorti de la cour j'ai mâché le bout de mes crayons j'ai fait un autobus avec mon efface avec des bonhommes dans les fenêtres j'ai fait une dictée j'ai écrit caoutchouc il y a eu les métiers facteur électricien menuisier plombier et les professions avocat médecin professeur député et les vocations prêtre missionnaire comme le cardinal Léger 
j'ai demandé moi qu'est-ce que je suis?

je n'étais qu'un enfant

j'ai ri

j'ai demandé pardon au professeur

je ne savais pas

j'ai dû être attentif

être sage

j'ai attendu la cloche

pour mettre mes bottes

j'ai menti

j'ai trouvé ça drôle

j'ai eu honte

j'ai copié une page de dictionnaire

j'ai acheté cinq petits chinois

je suis allé à l'église

je me suis mis à genoux

j'ai communié

un petit morceau de Bon Dieu

j'ai gardé le respect

on m'a demandé

les dix commandements de Dieu

j'en ai oubliés

on m'a mis en pénitence

j'ai pleuré

j'ai pleuré

j'ai pleuré

on m'a vraiment tout appris

et je n'ai vraiment su que pleurer

à l'abri des grands. 


\section{SOIR D'HALLOWEEN}

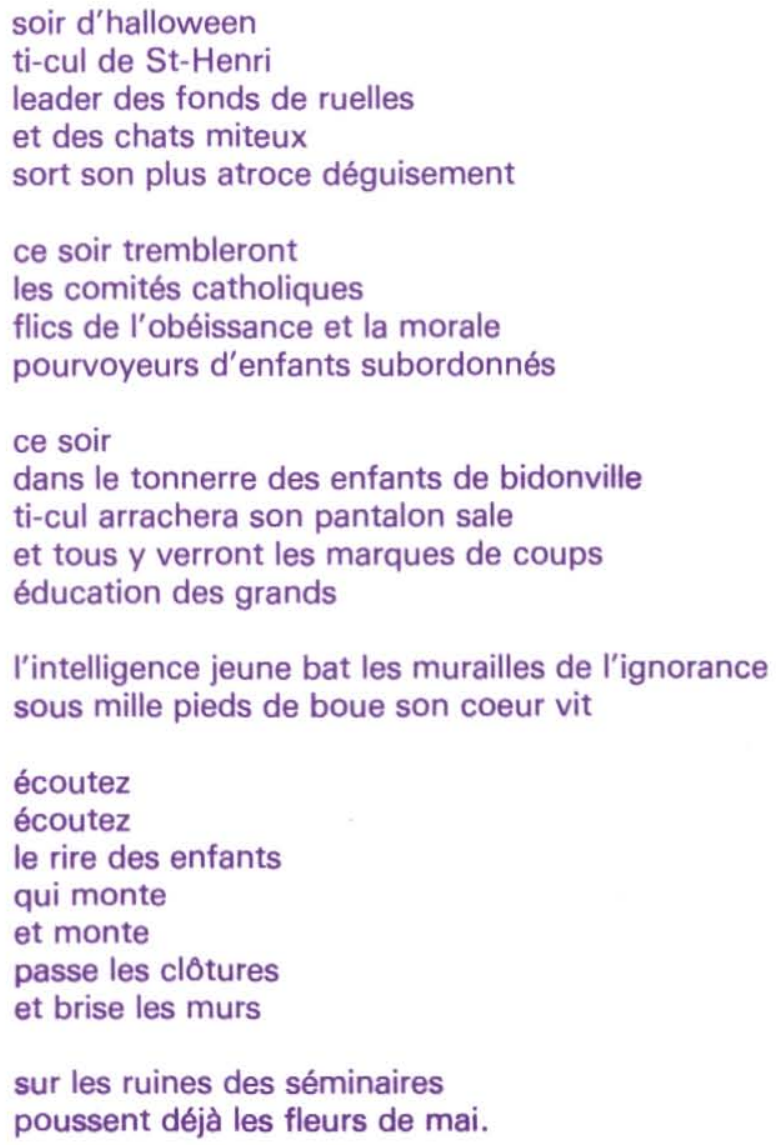




\section{LA SAINTE LEC̣ON}

l'ombre d'une grande soutane noire obscurcissait le ciel une église grassement nourrie appelait ses fidèles à exalter l'ignorance et la misère dans une grande maison dans un grand salon verni évêques et grands élus portaient à leurs lèvres calices et coupes d'argent on célébrait encore un grand moment certains discouraient avec une très grande habileté I'un d'eux dit hautement ceci:

"Certains prêtent l'oreille à un parvenu qui s'est efforcé de montrer que c'est la terre qui tourne et non les cieux et le firmament. Quiconque veut paraître habile doit imaginer quelque système nouveau qui, de tous les systèmes est naturellement le meilleur. Mais I'Ecriture Sainte dit que Josué ordonna au soleil de s'arrêter et non à la terre".

tous approuvèrent

et s'exclamèrent de satisfaction la terre fit un tour et l'avenir s'endormit sur ceux qui priaient. 


\section{FAIS-MOI L'AMOUR ENCORE UNE FOIS}

le bruit des rues

frappe à ta fenêtre

et tu n'y réponds plus

la mer se retire

dans sa chambre grise

où règne ce silence

qui te dissimule

tu baignes tes idées

dans des caresses interminables

ils naviguent

infatigables

dans le creux de ton lit

je divague sur ta nuque blanche

ta cuisse chaude se lève

entraînant derrière elle

ta jambe entièrement nue

une ombre

presqu'un tissu d'histoire

couvre encore ton corps

tes seins sensibles

tu parlais longtemps

tu tournais toutes les pages

et maintenant

ton corps envahi

tu penses en silence

chacune de nos caresses

tu veilles I'amour

comme on veille un enfant

tu es presqu'entière

dans les ruines de la vie

fais-moi l'amour

fais-moi l'amour

fais-moi l'amour

encore une fois. 


\section{PAROLES DU SILENCE}

de la nuit de l'hiver

de la caverne des songes

s'éveille la femme sans mots

la muette

la folle

de connivence avec le ven:

son histoire vieille comme le temps

elle use de rafales et de grincements

qui hantent les chambres

des filles du pays

de plaintes refoulées

jamais écoutées

de la servitude

la déraison et l'oubli

elle arrache les racines

coeur des générations sombres

où chauffe encore

une braise ardente

qui forge les consciences

clé des bouches

qui ouvre la parole

le dire des femmes

qui perce lentement. 